\title{
Drosophila Middle-Term Memory: Amnesiac is Required for PKA Activation in the Mushroom Bodies, a Function Modulated by Neprilysin 1
}

\author{
Oriane Turrel, Yasmine Rabah, Pierre-Yves Plaçais, ${ }^{-}$Valérie Goguel, ${ }^{*}$ and ${ }^{\circledR}$ Thomas Preat $^{*}$ \\ Genes and Dynamics of Memory Systems, Brain Plasticity Unit, CNRS, ESPCI Paris, PSL Research University, Paris 75005, France
}

In Drosophila, the mushroom bodies (MB) constitute the central brain structure for olfactory associative memory. As in mammals, the cAMP/PKA pathway plays a key role in memory formation. In the MB, Rutabaga (Rut) adenylate cyclase acts as a coincidence detector during associative conditioning to integrate calcium influx resulting from acetylcholine stimulation and G-protein activation resulting from dopaminergic stimulation. Amnesiac encodes a secreted neuropeptide required in the MB for two phases of aversive olfactory memory. Previous sequence analysis has revealed strong homology with the mammalian pituitary adenylate cyclase-activating peptide (PACAP). Here, we examined whether amnesiac is involved in cAMP/PKA dynamics in response to dopamine and acetylcholine co-stimulation in living flies. Experiments were conducted with both sexes, or with either sex. Our data show that amnesiac is necessary for the PKA activation process that results from coincidence detection in the MB. Since PACAP peptide is cleaved by the human membrane neprilysin hNEP, we searched for an interaction between Amnesiac and Neprilysin 1 (Nep1), a fly neprilysin involved in memory. We show that when Nep1 expression is acutely knocked down in adult MB, memory deficits displayed by amn hypomorphic mutants are rescued. Consistently, Nep1 inhibition also restores normal PKA activation in amn mutant flies. Taken together, the results suggest that Nep1 targets Amnesiac degradation to terminate its signaling function. Our work thus highlights a key role for Amnesiac in establishing within the MB the PKA dynamics that sustain middle-term memory (MTM) formation, a function modulated by Nep1.

Key words: Amnesiac; coincidence detection; Drosophila olfactory memory; mushroom body; Neprilysin; PKA

Significance Statement

The Drosophila amnesiac gene encodes a secreted neuropeptide whose expression is required for specific memory phases in the mushroom bodies (MB), the olfactory memory center. Here, we show that Amnesiac is required for PKA activation resulting from coincidence detection, a mechanism by which the MB integrate two spatially distinct stimuli to encode associative memory. Furthermore, our results uncover a functional relationship between Amnesiac and Neprilysin 1 (Nep1), a membrane peptidase involved in memory and expressed in the MB. These results suggest that Nep1 modulates Amnesiac levels. We propose that on conditioning, Amnesiac release from the MB allows, via an autocrine process, the sustaining of PKA activationmediating memory, which subsequently is inactivated by Nep1 degradation.

Received Sep. 25, 2019; revised Mar. 30, 2020; accepted Apr. 5, 2020

Author contributions: 0.T., V.G., and T.P. designed research; 0.T., Y.R., and V.G. performed research; 0.T., V.G., and T.P. analyzed data; P.-Y.P., V.G., and T.P. wrote the paper.

*V.G. and T.P. contributed equally to this work.

The authors declare no competing financial interests.

T.P. was supported by the Fondation pour la Recherche Médicale Grant DEQ20140329540. We thank Gonzalo Ortiz-Álvarez, Aurélie Lampin-Saint-Amaux, Honorine Lucchi, and Laure Pasquer for technical help. We also thank all the members of our laboratory for valuable discussions and for critically reading this manuscript.

0. Turrel's present address: Institute for Biology/Genetics, Freie Universitat Berlin, Berlin 14195, Germany.

V. Goguel's present address: Institut de Biologie Paris-Seine, CNRS - Sorbonne Université - INSERM 7-9 Quai St-Bernard, Paris 75005, France.

Correspondence should be addressed to Valérie Goguel at valerie.goguel@upmc.fr or Thomas Preat at thomas. preat@espci.fr.

https://doi.org/10.1523/JNEUROSCI.2311-19.2020

Copyright $(2020$ the authors

\section{Introduction}

Associative learning, which temporally pairs a conditioned stimulus (CS) to an unconditioned stimulus (US), is a powerful way of acquiring adaptive behavior. At the molecular and cellular levels, the association between CS and US is mediated by coincidence detection mechanisms that reflect the superadditive activation of a molecular pathway in the presence of both stimuli. One of the major coincidence detectors is the cAMP/PKA pathway, which depends on Type-I adenylate cyclases stimulated by both calcium/calmodulin, via acetylcholine signaling representing the CS, and G-protein coupled to dopamine metabotropic receptors activated by dopaminergic neurons encoding the US (Mons et al., 1999). 
In Drosophila, the mushroom bodies (MB) constitute the central integrative brain structure for olfactory memory (de Belle and Heisenberg, 1994). The MB are composed of 4000 intrinsic neurons called Kenyon cells (KC), and classed into three subtypes whose axons form two vertical ( $\alpha$ and $\alpha^{\prime}$ ) and three medial $\left(\beta, \beta^{\prime}\right.$, and $\left.\gamma\right)$ lobes (Crittenden et al., 1998). Using a classical conditioning paradigm in which an odorant (CS) was paired to electric shocks (US), Bouzaiane et al. (2015) revealed that flies are capable of forming six discrete memory phases reflected at the neural network level. Among these phases are middle-term memory (MTM) and long-term memory (LTM), which are both encoded in $\alpha / \beta$ KC. As in mammals, the fly cAMP/PKA pathway plays a key role in associative memory, wherein the adenylate cyclase Rutabaga (Rut) acts as a coincidence detector in the MB to associate the CS and US pathways (Levin et al., 1992; Tomchik and Davis, 2009; Gervasi et al., 2010).

The amnesiac Drosophila mutant ( $\mathrm{amn}$ ) was isolated in a memory defect behavioral screen (Quinn et al., 1979). As with other components of the cAMP/PKA pathway involved in Drosophila memory, amn is expressed in the MB (Shih et al., 2019). We recently showed that amn expression in the $\mathrm{MB}$ is specifically required for MTM and LTM (Turrel et al., 2018). amn encodes a neuropeptide precursor with a signal sequence (Feany and Quinn, 1995). Sequence analyses suggest the existence of three peptides, with one of them homologous to mammalian pituitary adenylate cyclase-activating peptide (PACAP) (Feany and Quinn, 1995; Hashimoto et al., 2002). PACAP is widely expressed throughout the brain, acting as a neuromodulator or neurotrophic factor through activation of G-protein-linked receptors to regulate a variety of physiological processes through stimulation of cAMP production (Miyata et al., 1989; Arimura, 1998; Vaudry et al., 2000). Furthermore, PACAP may exert a role in learning and memory (Sacchetti et al., 2001; Hashimoto et al., 2002; Matsuyama et al., 2003; Schmidt et al., 2015).

After its release, a neurotransmitter's action is terminated either by diffusion, re-uptake by the presynaptic neuron, or enzymatic degradation. In contrast, neuropeptide signaling is exclusively terminated by enzymatic degradation (Russo, 2017). Possible enzyme candidates include neprilysins, type 1 metalloproteinases whose main function is the degradation of signaling peptides at the cell surface (Turner et al., 2001). Indeed, the human neprilysin hNEP is capable of cleaving a PACAP neuropeptide (Gourlet et al., 1997). Drosophila express four neprilysins (Bland et al., 2008; Meyer et al., 2011) that are all required for MTM and LTM, establishing that neuropeptide degradation is a central process for memory formation (Turrel et al., 2016). Among the four neprilysins, Neprilysin 1 (Nep1) is the only one whose expression is required for MTM in the MB (Turrel et al., 2016).

Here, we aimed to confirm whether AMN intervenes in memory by modulating cAMP concentration, as suggested by its sequence homology. For this, we analyzed PKA dynamics in the $\mathrm{MB}$ vertical lobes. Our results show that amn mutant brains fail to display PKA activation in the $\alpha$ lobe in response to co-application of dopamine and acetylcholine. We then searched whether Nep is involved in terminating AMN action. Using RNAi, we show that Nep1 knock-down restores normal MTM and normal PKA dynamics in amn mutants, establishing a functional interaction between Nep1 and AMN in the MB.

\section{Materials and Methods}

Drosophila stocks

Drosophila melanogaster wild-type Canton Special (CS) and mutant flies were raised on standard medium at $18^{\circ} \mathrm{C}$ in $60 \%$ humidity in a $12 / 12 \mathrm{~h}$ light/dark cycle. UAS-RNAi lines were obtained from the Vienna Drosophila Resource Center (VDRC; $a m n^{R N A i}$ : ID 5606; Nep1 $1^{R N A i 2}$ : ID 108860 ) and from the National Institute of Genetics (NIG; Nep1 $1^{\text {RNAi1 }}$ : ID 5894-R3). Gal4 drivers were used to achieve RNAi expression. The $238 Y$ and $c 739$ drivers were used for expression in the $\mathrm{MB}$, and in $\alpha / \beta$ neurons, respectively. tubulin-Gal80 $0^{t s}\left(G^{2} l 80^{t s}\right)$ was used for conditional expression in the adult. The $a m n^{X 8}$-null mutant line is described in Moore et al. (1998). To specifically induce RNAi expression in adults, Gal $80^{t s}$ was inactivated by keeping flies at $30^{\circ} \mathrm{C}$ for $3 \mathrm{~d}$ before conditioning, as described by McGuire et al. (2003). Rescue experiments were conducted with the UAS-amn construct $\left(a m n^{+}\right)$described in Waddell et al. (2000). For Nep1 overexpression, a KpnI-PCR fragment (PfuUltra HF DNA polymerase, Agilent) encompassing the Nepl coding sequence was generated using the GH03315 Nep1 cDNA (Rubin et al., 2000). The following oligonucleotides were used: 5 '-CCCCCCGGTACCCCATAGTA GAAGATGTCG $-3^{\prime}$ (forward) and $5^{\prime}$-CCCCCCGGTACCGCGGC GGACTACCAC $-3^{\prime}$ (reverse) where KpnI sites are underlined. The PCR fragment was subjected to KpnI digestion (New England BioLabs) and purified from agarose gel (QIAquick Gel Extraction kit, QIAGEN) before cloning into the pUAST vector (Brand and Perrimon, 1993) digested by KpnI. Resulting clones were verified by multiple digestion and sequencing. The pUAST-Nep1 plasmid was injected into the CS line (Rainbow Transgenic Flies, Inc) to create the UAS-Nep1 line $\left(\mathrm{Nep}^{+}\right)$.

\section{Behavioral experiments}

Flies were trained with classical olfactory aversive conditioning protocols as described by Pascual and Préat (2001). Training and testing were performed at $25^{\circ} \mathrm{C}$ in $80 \%$ humidity. Conditioning was performed on samples of 25-35 flies aged 3-4 d using $0.360 \mathrm{~mm} 3$-octanol ( $\sim 95 \%$ purity, Sigma-Aldrich) and $0.325 \mathrm{~mm}$ 4-methylcyclohexanol (99\% purity, Sigma-Aldrich). Odors were diluted in paraffin oil (VWR International). Memory tests were performed with a T-maze apparatus (Tully and Quinn, 1985). Flies were given 1 min to choose between two arms, each delivering a distinct odor. An index was calculated as the difference between the numbers of flies in each arm divided by the sum of flies in both arms. The average of two reciprocal experiments gave a performance index (PI). To assess MTM, flies were submitted to one-cycle training, and memory was tested $2 \mathrm{~h}$ later.

\section{Quantitative PCR analyses}

Flies were raised at $25^{\circ} \mathrm{C}$ and further incubated for $3 \mathrm{~d}$ at $30^{\circ} \mathrm{C}$ in the case of Gal4 induction. Total RNA was extracted from 60 female heads using the RNeasy Plant Mini kit (QIAGEN). Preparations were treated with DNaseI (Biolabs) for $15 \mathrm{~min}$ at $37^{\circ} \mathrm{C}$. DNase was heat-inactivated with EDTA (10 mM). Samples were cleaned with the RNeasy MinElute Cleanup kit (QIAGEN), and reverse-transcribed with oligo(dT)20 primers using the SuperScript III First-Strand kit (Life Technologies) according to the manufacturer's instructions. The amn oligonucleotides were as previously described (Turrel et al., 2018). The target cDNA level was compared against the level of $\alpha$-Tub84B (Tub, CG1913) cDNA, which was used as a reference. Amplification was performed using a LightCycler 480 (Roche) and the SYBR Green I Master mix (Roche). Reactions were conducted in triplicate. Specificity and size of amplification products were assessed by melting curve analyses and agarose gel electrophoresis, respectively. Expression relative to the reference was expressed as a ratio ( $2^{-\Delta \mathrm{Cp}}$, where $\mathrm{Cp}$ is the crossing point).

\section{Live imaging}

Preparation of flies for live imaging was performed as previously described (Fiala and Spall, 2003). Untrained flies were removed from culture bottles and glued to a plastic coverslip coated with a thin transparent plastic sheet. The coverslip was then placed in the recording chamber and a drop of Drosophila Ringer's solution was placed over the head (130 mm NaCl, $5 \mathrm{~mm} \mathrm{KCl}, 2 \mathrm{~mm} \mathrm{MgCl} 2,2 \mathrm{~mm} \mathrm{CaCl}$, $36 \mathrm{~mm} \mathrm{su}-$ crose, and 5 mм HEPES-NaOH; pH 7.3). A small region of cuticle was cut away from the top of the head capsule, and tracheae were removed from the area. Flies were then placed under a Leica TCS-SP5 microscope and observed with a $25 \times$ water-immersion objective (NA $=0.95$, Leica). Experiments were performed at room temperature and brains were 

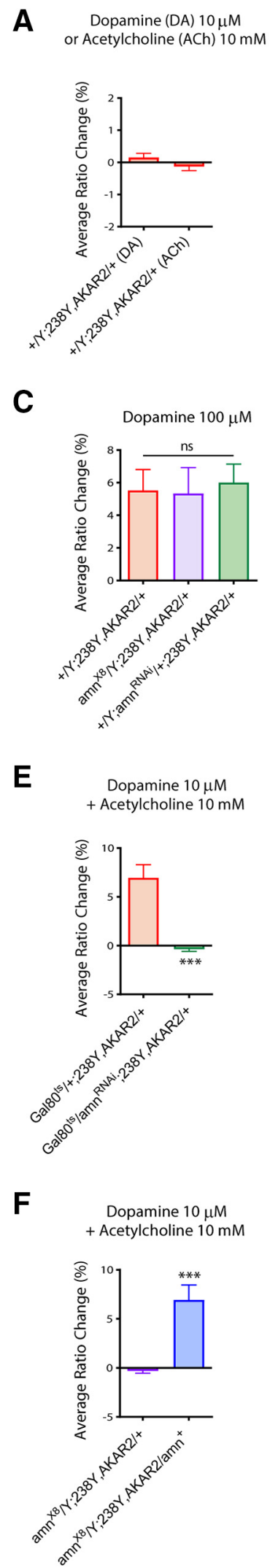



D Acetylcholine $10 \mathrm{mM}$

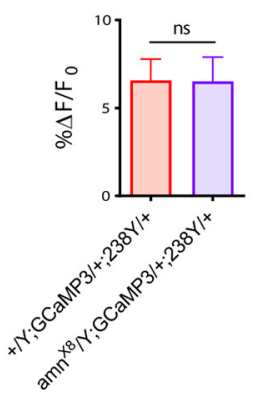


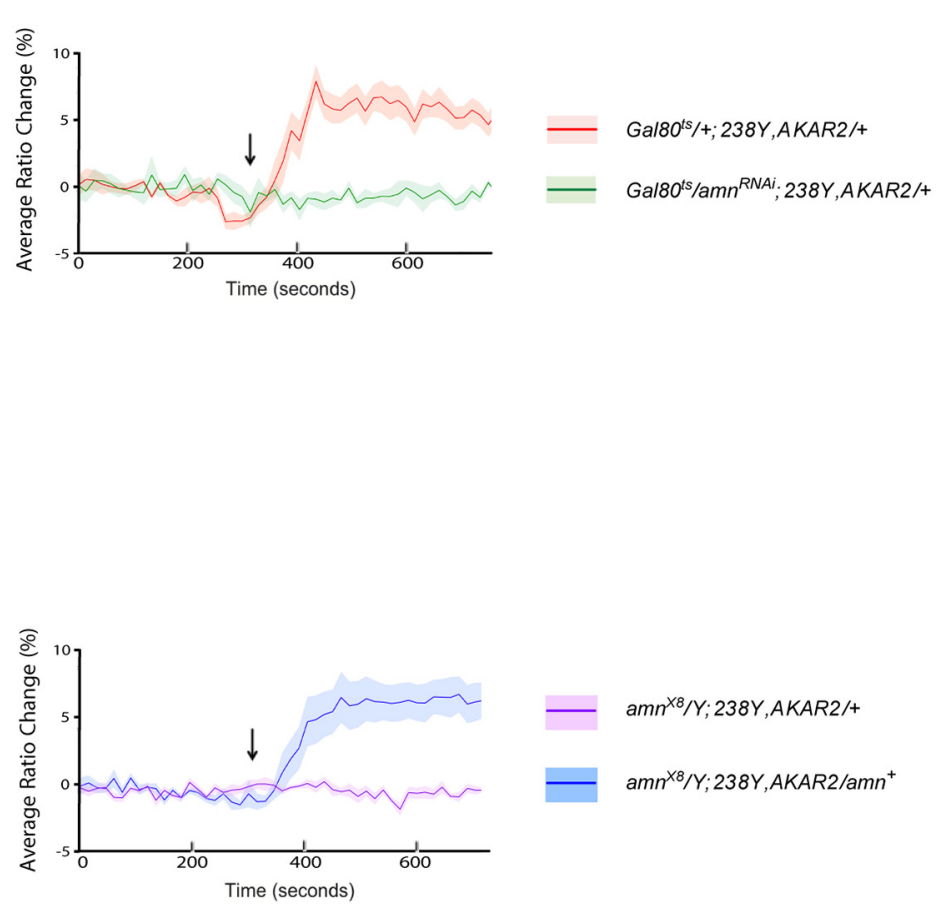

Figure 1. PKA activation in the MB vertical lobes after coincidence detection is abolished in amn-deficient flies. Either the PKA AKAR2 FRET probe or the calcium GCaMP3 probe was expressed in the MB with the $238 \mathrm{Y} \mathrm{Gal} 4$ driver. Only males were analyzed. $A$, Bath application of either dopamine (DA; $10 \mu \mathrm{M}$ ) or acetylcholine (ACh; $10 \mathrm{~mm}$ ) does not induce PKA activation in the vertical lobes $\left(t\right.$ test, $\left.t_{(18)}=1.549, p=0.139, n=10\right)$. B, PKA is activated on co-stimulation of DA and ACh in $+/ Y ; 238 Y, A K A R 2 /+$ control flies. In contrast, DA and ACh c0-application does not lead to PKA activation in amn mutant fly brains. Mean FRET ratio changes in the vertical lobe are shown in response to co-application of $D A$ and $A C h\left(F_{(2,29)}=9.301\right.$, *** $p=0.0008$, $n=10$ ). Asterisks denote the pairwise post hoc comparisons between the genotype of interest and the $+/ Y ; 238 Y, A K A R 2 /+$ control, following the usual nomenclature. Right panel, Grouped time course of FRET ratios. Graphs were produced using the same data as for the bar graph. The arrow indicates the time of neurotransmitter application. C, DA application at high 
continuously perfused with Drosophila Ringer's solution. Four frames were acquired per minute during live imaging. For AKAR2-FRET experiments, two-photon excitation was obtained using a mode-locked Ti:sapphire laser (Mai Tai, Spectra Physics) set at $860 \mathrm{~nm}$. The specifications of the detection channels were identical to those described in Gervasi et al. (2010). Scanning and acquisition were controlled by the LAS AF software (Leica). CFP and YFP images $(512 \times 512$ pixels) were acquired simultaneously with a line rate of $400 \mathrm{~Hz}$. To analyze the calcium response, the GCaMP3 probe was excited by the 488-nm line of an argon laser, with scanning at a line rate of $400 \mathrm{~Hz}$. Fluorescence-induced light emission was collected by a photomultiplier in the $505-$ to $555-\mathrm{nm}$ wavelength range.

Image analyses

To obtain FRET ratio time courses, CFP and YFP images were background subtracted at each time point, in which the background was evaluated as the mean intensity over a region of interest placed in a nonfluorescent part of the brain. YFP and CFP emission intensities for each image were then averaged within a region of interest delimited by hand and surrounding the $\alpha$ lobes of the MB. These values were used to calculate the yellow/cyan emission ratio, which was then normalized to the baseline ratio. The baseline consists of the first 20 time points of the acquisition. Dopamine and acetylcholine (Sigma-Aldrich) were applied immediately after the 20th time point ( $300 \mathrm{~s}$ ), and analyses were made on a segment of acquisition time from 500 to 700 s. Photobleaching compensation, determined during the baseline, was applied for all flies from each experiment.

Statistical analyses

Comparisons of the data series between two conditions were achieved by a two-tailed unpaired Student's $t$ test. Results of $t$ tests are given as the value $t_{(\mathrm{x})}$ of the $t$ distribution with $\mathrm{x}$ degrees of freedom obtained from the data. Comparisons between more than two distinct groups were made using one-way analysis of variance, which were followed (if significant at $p \leq 0.05$ ) by Newman-Keuls multiple comparisons tests. The overall analysis of variance $p$ value is provided in the legends along with the value of the corresponding Fisher distribution $F_{(\mathrm{x}, \mathrm{y})}$, where $\mathrm{x}$ is the number of degrees of freedom for groups and $y$ is the total number of degrees of freedom for the distribution. Asterisks on the figure denote the least significant of the pairwise post hoc comparisons between the genotype of interest and its controls, following the usual nomenclature. Statistical tests were performed using the GraphPad Prism 5 software. All data are displayed as mean \pm SEM.

\section{Results}

PKA activation following coincidence detection in MB vertical lobes is abolished in amn mutant flies

It was shown that a PACAP-like peptide with an apparent molecular weight compatible with AMN sequence exists in the fly

$\leftarrow$

concentration induces normal PKA activation in amn mutant flies. Mean FRET ratio changes in the vertical lobes are shown in response to DA application at high concentration (100 $\mu \mathrm{M}) . a m n^{X 8} / Y_{;} 238 Y, A K A R 2 /+$ and $+N ; a m n^{R N A i} /+; 238 Y, A K A R 2 /+$ flies show similar FRET ratios as $+/ Y ; 238 Y, A K A R 2 /+$ control flies $\left(F_{(2,29)}=0.066, p=0.936, n=10\right)$. $\boldsymbol{D}$, ACh application induces a normal calcium response in amn mutant flies. Mean FRET ratio changes in the vertical lobes are shown in response to ACh application (10 mM). $a m n^{X 8} / Y$; GCaMP3/ $+; 238 Y /+$ flies show similar ratios as $+/ Y ; G C a M P 3 /+; 238 Y /+$ control flies $\left(t\right.$ test, $t_{(14)}=$ $0.033, p=0.974, n=8)$. $\boldsymbol{E}$, Acute inhibition of amn expression in the adult MB prevents coincidence detection. Mean FRET ratio changes in the vertical lobe are shown in response to co-application of DA and ACh ( $t$ test, $t_{(14)}=5.302,{ }^{* * *} p=0.0001, n=8$ ). Right panel, Grouped time course of FRET ratios. Graphs were produced using the same data as for the bar graph. The arrow indicates the time of neurotransmitter application. $\boldsymbol{F}$, amn expression in the MB of $a m n^{X 8} / Y$ mutant flies restores coincidence detection. Mean FRET ratio changes in the vertical lobe are shown in response to the paired application of DA and ACh ( $t$ test, $t_{(15)}=4.477,{ }^{* * *} p=0.0004, n \geq 8$ ). Right panel, Grouped time course of FRET ratios. Graphs were produced using the same data as for the bar graph. The arrow indicates the time of neurotransmitter application. ns, not significant.
(Zhong and Peña, 1995). To investigate AMN as a putative adenylate cyclase-activating peptide, we first analyzed PKA dynamics in $\mathrm{MB}$ neurons of $a m n^{X 8}$ null mutant flies that contain a genomic deletion of the amn open reading frame (Moore et al., 1998). In response to both dopamine (which represents the US) and acetylcholine (which mimics the CS and leads to an increase in intracellular calcium), the Drosophila adenylate cyclase Rut mediates coincidence detection through an increase in cAMP concentration, resulting in PKA activation in the vertical lobes (Tomchik and Davis, 2009; Gervasi et al., 2010). This PKA activation observed with artificial stimulation is used as a proxy to study coincidence detection events that are thought to occur during actual conditioning. Using a two-photon microscope, we conducted in vivo imaging of the PKA FRET probe AKAR2 (Zhang et al., 2001, 2005) expressed in the MB (Gervasi et al., 2010). As previously shown (Gervasi et al., 2010), stimulation of control brains $(+/ Y ; 238 Y, A K A R 2 /+)$ with either $10 \mu \mathrm{M}$ dopamine or $10 \mathrm{~mm}$ acetylcholine did not lead to PKA activation in the vertical lobes (Fig. 1A) whereas co-stimulation did (Fig. 1B), thus demonstrating that coincidence detection occurred. In sharp contrast, co-stimulation of $a m n^{X 8} / Y$ null mutant brains did not induce PKA activation in the vertical lobes (Fig. 1B), suggesting that coincidence detection did not occur. To analyze the effect of amn reduction in the $\mathrm{MB}$, we targeted amn expression with a UAS-RNAi construct $\left(a m n^{R N A i}\right)$ previously shown to phenocopy amn mutant defects (Aldrich et al., 2010; Turrel et al., 2018). We thus observed that like $a m n^{X 8} / Y$ null flies, specific inhibition of amn expression in the MB led to defective coincidence detection following brain co-stimulation with dopamine and acetylcholine (Fig. 1B).

Next, we analyzed the effect of brain bath application of 100 $\mu \mathrm{M}$ dopamine, a higher concentration known to activate Rut (Gervasi et al., 2010). As previously described, flies expressing the AKAR2 probe in the MB $(+/ Y ; 238 Y, A K A R 2 /+)$ showed an increase in FRET ratio in the vertical lobes under these conditions (Fig. 1C). Stimulation with $100 \mu \mathrm{M}$ dopamine also induced increased PKA activity in $a m n^{X 8} / Y ; 238 Y, A K A R 2 /+$ brains (Fig. $1 C)$. Similar results were obtained with $a m n^{R N A i}$-expressing flies (Fig. 1C), showing that $\mathrm{AMN}$ is not required for Rut to respond to high levels of dopamine. We further analyzed whether amn knock-out influences calcium signaling in the MB following acetylcholine application using the GCaMP3 probe (Tian et al., 2009). We thus observed that $a m n^{X 8}$ null flies exhibit a normal MB calcium response (Fig. 1D). This confirms that the inability of amn mutant brains to respond to co-application of acetylcholine and dopamine is neither caused by a defect in calcium signaling, nor by the inability of Rut to respond to a high concentration of dopamine.

These results were reinforced by assessing PKA dynamics under adult stage-specific acute amn downregulation. In order to restrict $a m n^{R N A i}$ expression to adulthood, we took advantage of the TARGET system (McGuire et al., 2003), which relies on a temperature-sensitive Gal80 inhibitor that represses Gal4 transcriptional activity at low temperature, while this inhibition is lifted at high temperature $\left(30^{\circ} \mathrm{C}\right)$. Experiments were performed with a tub-Galso ${ }^{t s}$ line $\left(G a l 80^{t s}\right)$ and after $3 \mathrm{~d}$ of induction, $\mathrm{Gal}^{t} 0^{t s}, a m n^{R N A i} /+; 238 Y, A K A R 2 /+$ flies showed defective coincidence detection following brain co-stimulation with dopamine and acetylcholine (Fig. 1E).

Lastly, we investigated whether restoring amn expression in the $\mathrm{MB}$ of $a m n^{X 8}$ flies could restore coincidence detection. We observed that $a m n^{X 8} / Y ; 238 Y, A K A R 2 / a m n^{+}$flies responded efficiently to coapplied dopamine and acetylcholine (Fig. 1F). Thus, amn expression in the MB is sufficient to restore normal PKA activation. 
A


C

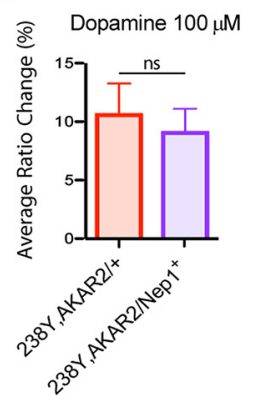



D

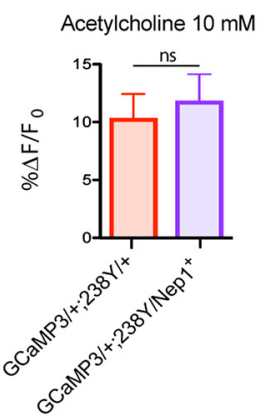

Figure 2. Nep1 overexpression in the MB of adult flies impairs MTM and PKA activation. A, Acute Nep1 overexpression in the $\alpha / \beta$ KC of adult flies impairs MTM. Left panel, Flies were incubated for $3 \mathrm{~d}$ at $30^{\circ} \mathrm{C}$ to achieve Nep1 overexpression. Gal80 $0^{\text {ts }}, \mathrm{C} 739 /+$;Nep $1^{+} /+$ flies exhibit lower memory scores than their genetic controls $\left(F_{(2,53)}=7.578,{ }^{* *} p=0.0013\right.$, $n=18)$. Right panel, In the absence of induction, Gal80 ${ }^{t s},\left(739 /+; N e p 1^{+} /+\right.$flies exhibit memory scores similar to their genetic controls $\left(F_{(2,29)}=0.255, p=0.777, n=10\right)$. Asterisk denotes the least significant of the pairwise post hoc comparisons between the genotype of interest and its controls, following the usual nomenclature. $\boldsymbol{B}$, Nep1 overexpression impairs PKA activation in the MB vertical lobe after coincidence detection. Dopamine and acetylcholine co-application leads to PKA activation in 238Y,AKAR2/+ control flies, but not in 238Y, $A K A R 2 / \mathrm{Nep}^{+}$fly brains. Left panel, Mean FRET ratio changes in the vertical lobe are shown in response to co-application of dopamine and acetylcholine ( $t$ test, $t_{(17)}=3.753$, $\left.{ }^{* *} p=0.0016, n \geq 9\right)$. Right panel, Grouped time course of FRET ratios. Graphs were produced using the same data as for the bar graph. The arrow indicates the time of neurotransmitter application. C, Dopamine application at high concentration induces normal PKA activation in flies overexpressing Nep1 in the MB. Mean FRET ratio changes in the vertical lobes are shown in response to dopamine application at high concentration $(100 \mu \mathrm{m}) .238 \mathrm{Y}$, AKAR2/Nep $1^{+}$flies show similar FRET ratios as 238Y,AKAR2/+ control flies ( $t$ test, $t_{(16)}=$ $0.460, p=0.652, n=9) . \boldsymbol{D}$, Acetylcholine application induces a normal calcium response in flies overexpressing Nep1. Mean FRET ratio changes in the vertical lobes are shown in response to acetylcholine application (10 mM). GCaMP3/ $+; 238 Y / N e p 1^{+}$flies show similar ratios as GCaMP3/+;238Y/+ control flies ( $t$ test, $t_{(14)}=0.455, p=0.656, n=8$ ). ns, not significant.

Taken together, these results establish that amn expression in the $\mathrm{MB}$ is required for the PKA activation process that occurs on costimulation, consistent with an adenylate cyclase-activating function (Bhattacharya et al., 2004).

\section{Nep1 overexpression impairs MTM and prevents PKA activation following coincidence detection}

Previously, it was shown that human PACAP peptide is degraded in vitro by hNEP (Gourlet et al., 1997). Interestingly, Drosophila Nep1 is expressed in the MB (Sitnik et al., 2014), and is involved in the adult $\mathrm{MB}$ in the same memory phases as AMN (Turrel et al., 2016), raising the question of whether in the fly, Nep1 interacts with AMN. We reasoned that if the Nep1 protease targets AMN peptide, Nep1 overexpression should cause the same phenotype as the amn deficiency. To assess this hypothesis, we examined MTM in flies overexpressing Nep1 in the adult MB. To this end we used a UAS-Nep1 construct (Nep1 ${ }^{+}$, Materials and Methods) in combination with the tubulin-Gal80 ${ }^{t s}, c 739$ Gal4 driver $\left(G a l 80^{t s}\right.$, c739; Aso et al., 2009). To analyze memory, we used a classical conditioning paradigm in which an odor is paired with electric shocks. Here, groups of flies were successively exposed to two distinct odors, only one of which was associated with the delivery of voltage pulses. MTM was then assessed $2 \mathrm{~h}$ after a single conditioning. After induction, Gal $80^{t s}, c 739 /+; N e p 1^{+} /+$flies showed impaired MTM (Fig. 2A). In contrast, in the absence of Gal4 induction, MTM was normal (Fig. $2 A$ ). The ability of these flies to avoid electric shocks and their olfactory acuity to each odor after electric shock was unaffected (Table 1), showing that they displayed normal perception of the conditioning stimuli. We conclude that Nep1 overexpression in the adult MB is deleterious for MTM.

We next examined PKA dynamics in the MB of flies overexpressing Nep1. Following co-application of dopamine and acetylcholine, we did not observed PKA activation in 238Y,AKAR2/ $N e p 1^{+}$brains (Fig. 2B). We verified that PKA activation on application of dopamine at high concentration was not impaired by Nep1 overexpression (Fig. 2C). Likewise, Nep1 overexpression did not alter calcium signaling (Fig. 2D). We conclude that, as is the case for amn deficiency, Nep1 overexpression in the MB abolishes PKA dynamics on coincidence detection. Taken together, the data show that Nep1 overexpression leads to phenotypes similar to that of amn deficiency, consistent with the possibility that Nep1 functionally interacts with AMN.

\section{Nep1 knock-down restores wild-type MTM and PKA activation in amn mutant flies}

To investigate a potential interaction between AMN and Nep1, we wanted to knock down Nep1 expression in amn-deficient flies and analyze MTM. The $a m n^{X 8}$ null mutant line results from the excision of one of two Gal4-encoding P-elements inserted in the $a m n^{28 A}$ line (Moore et al., 1998), with $a m n^{X 8}$ flies thus retaining Gal4 activity that is localized in the MB (Keene et al., 2004; Turrel et al., 2018). This line could thus be used in combination with Nep1 RNAi $\left(N e p 1^{R N A i 1}\right)$ to knock down Nep1 in MB neurons in an amn-deficient context. As the amn gene is located on the $\mathrm{X}$ chromosome, while $a m n^{X 8} / Y$ hemizygous males do not express $a m n, a m n^{X 8} /+$ heterozygous female flies express $a m n$ levels twice lower than wild-type levels.

We previously showed that amn loss of function achieved by $a m n^{R N A i}$ expression in the MB results in MTM impairment (Turrel et al., 2018). Consistently, we observed here that $a m n^{X 8} /+$ hypomorph flies exhibited an MTM deficit (Fig. 3A). Strikingly, Nep1 knock-down in $a m n^{X 8} /+$ flies led to wild-type MTM (Fig. $3 A$ ), revealing a full rescue of the MTM deficit displayed by 
Table 1. Shock reactivity and olfactory acuity of flies overexpressing Nep1 in adult $\alpha / \beta$ neurons

\begin{tabular}{|c|c|c|c|}
\hline \multirow[b]{2}{*}{ Genotype } & \multirow[b]{2}{*}{ Shock reactivity } & \multicolumn{2}{|c|}{ Olfactory acuity } \\
\hline & & Octanol & Methylcyclohexano \\
\hline Gal $80^{\text {ts }}, \mathrm{c} 739 /+$ & $65.52 \pm 9.17$ & $48.25 \pm 8.27$ & $44.63 \pm 7.03$ \\
\hline Gal80 $0^{\text {ts }}, \mathrm{c739} /+; \mathrm{Nep1}^{+} /+$ & $62.18 \pm 9.52$ & $54.29 \pm 8.45$ & $47.50 \pm 8.12$ \\
\hline $\mathrm{Nep}^{+} /+$ & $58.04 \pm 9.38$ & $52.63 \pm 6.44$ & $51.75 \pm 8.73$ \\
\hline
\end{tabular}

Data are shown as mean \pm SEM. After $3 \mathrm{~d}$ of induction, neither shock reactivity $\left(F_{(2,35)}=0.160, p=0.853\right.$, $n=12)$ nor olfactory acuity for octanol $\left(F_{(2,22)}=0.163, p=0.851, n \geq 7\right)$ and methylcyclohexanol $\left(F_{(2,23)}=\right.$ $0.201, p=0.819, n=8)$ is impaired in flies overexpressing Nep1 under the control of the Gal $80^{t s}, c 739$ driver.

$a m n^{X 8} /+$ flies. We verified with qPCR experiments that Nep1 inhibition in $a m n^{X 8} /+$ flies did not result in the modification of amn mRNA levels (Fig. $3 A$ ), suggesting that the observed memory rescue is mediated at the AMN protein level. A simple hypothesis to account for these results is that Nep1 degrades the AMN peptide. In this scenario, Nep1 reduction would lead to an increase in the level of the AMN peptide, thereby restoring AMN to a level compatible with its normal function in memory. According to this hypothesis, Nep1 inhibition should not be able to rescue the memory deficit of $a m n^{X 8} / Y$ null mutant flies, as they do not express $A M N$. Indeed, our behavior experiments show that $a m n^{X 8} / Y$; $N e p 1^{R N A i 1} /+$ flies display an MTM deficit similar to $a m n^{X 8} / Y$ flies (Fig. 3B). This result demonstrates that the memory rescue observed on Nep1 inhibition in $a m n^{X 8} /+$ flies is dependent on AMN expression.

We next aimed to analyze the effect of Nep1 acute inhibition in adult $a m n^{X 8} /+$ female flies. As expected, when Gal4 transcription was not induced, $a m n^{X 8} /+; G a l 80^{t s} /+; N e p 1^{R N A i 1} /+$ flies exhibited an MTM deficit similar to that of $a m n^{X 8} /+; G a l 80^{t s} /+$ flies (Fig. 3C). In sharp contrast, when Gal4 transcription was induced, $a m n^{X 8} /+;$ Gal $80^{t s} /+; N e p 1^{R N A i 1} /+$ flies exhibited normal MTM scores (Fig. 3C). We conclude that Nep1 knock-down restricted to adulthood allows the rescue of the MTM deficit displayed by $a m n^{X 8} /+$ hypomorph flies. Taken together, these results establish a functional interaction between $a m n$ and Nep1 in the adult fly brain.

The discovery that AMN functionally interacts with Nep1 prompted us to analyze PKA dynamics. While $a m n^{X 8} /+; 238 Y$, $A K A R 2 /+$ flies did not show PKA activation on co-application of dopamine and acetylcholine, $a m n^{X 8} /+; 238 Y, A K A R 2 / N e p 1^{R N A i 1}$ flies markedly displayed PKA activation to a level similar to that of the control (Fig. 3D). This result indicates that Nep1 inhibition restores normal coincidence detection in $a m n^{X 8} /+$ flies.

\section{Nep1 knock-down in the adult MB of amn mutant flies restores wild-type MTM and PKA activation}

To address in greater detail the spatial relationship between $a m n$ and Nep1, we used the Gal80 ${ }^{t s}, c 739$ driver to achieve both $a m n$ and Nep1 inhibition in adult $\alpha / \beta$ MB neurons. Although Nep1 expression in $\alpha / \beta$ neurons is required for MTM (Turrel et al., 2016), Gal80 ${ }^{t s}, c 739 /+; N e p 1^{R N A i 1} /+$-induced flies displayed normal MTM (Fig. 4A). This result has already been reported, and can be explained by the fact that $N e p 1^{R N A i 1}$ does not allow inhibition of Nep1 expression at a level sufficient to alter MTM (Turrel et al., 2017). As expected (Turrel et al., 2018), $a m n^{R N A i}$ expression in adult $\alpha / \beta$ neurons mimicked the MTM deficit observed in $a m n^{X 8} /+$ flies (Fig. 4A). Furthermore, concomitant expression of $N e p 1^{R N A i 1}$ restored normal MTM (Fig. 4A). We considered that co-expression of two distinct Gal4 UAS transgenes might affect the expression level of each of them, via a Gal4 dilution effect. To rule out the possibility that the normal memory score displayed by $G a l 80^{t s}, c 739 / a m n^{R N A i} ; N e p 1^{R N A i 1} /+$-induced flies was caused by a reduced level of amn inhibition, we performed qPCR experiments to assess the level of amn expression. As expected, Gal80 ${ }^{t s}, c 739 / a m n^{R N A i}$ fly heads contained a reduced level of amn mRNA as compared with the control (Fig. $4 B$ ). Importantly, Gal80 ${ }^{t s}, c 739 / a m n^{R N A i} ; N e p 1^{R N A i 1} /+$ flies expressed a level of amn mRNA that was also reduced in comparison to the control, and which was not significantly different from flies expressing only $a m n^{R N A i}$ (Fig. $4 B$ ). We thus conclude that in adult $\alpha / \beta$ neurons, inhibition of Nep1 expression rescues the amn MTM impairment caused by $a m n$ inhibition, without affecting amn mRNA levels, implicating an effect that depends on AMN peptide level.

To confirm these results, we repeated behavior experiments with another non-overlapping RNAi construct, Nep1 $1^{\text {RNAi2 }}$ (Turrel et al., 2016). Unlike Nep1 $1^{R N A i 1}$ expression, Nep1 $1^{R N A i 2}$ expression in adult $\alpha / \beta$ neurons caused an MTM deficit (Fig. 4C). Strikingly, Gal80 ${ }^{t s}, c 739 / a m n^{R N A i}, N e p 1^{R N A i 2}$-induced flies showed normal MTM (Fig. 4C). We verified that co-expression of Nep1 $1^{\text {RNAi2 }}$ together with $a m n^{R N A i}$ did not modify the level of $a m n$ mRNA (Fig. $4 D$ ). Thus, while expression of either $a m n^{R N A i}$ or $N e p 1^{R N A i 2}$ is deleterious for MTM, their co-expression does not impact memory. These results reveal that in this context, no other substrate than AMN needs to be targeted by Nep1 to ensure normal MTM. In conclusion, acute knock-down of Nep1 in adult $\alpha / \beta$ neurons rescues the MTM deficit displayed by amn mutant flies demonstrating that both proteins are involved in the same pathway for memory formation.

We next analyzed PKA dynamics in flies expressing concomitantly amn and Nep1 RNAi in MB neurons. As already observed, $a m n^{R N A i} /+; 238 Y, A K A R 2 /+$ flies did not show any PKA activation following co-application of dopamine and acetylcholine (Fig. 4E). Co-expression of either the Nep1 $1^{\text {RNAi1 }}$ or Nep1 $1^{\text {RNAi2 }}$ construct restored PKA activation to a normal level (Fig. 4E). Taken together, our data demonstrate that Nep1 knock-down in $\alpha / \beta$ neurons restores normal PKA dynamics in amn mutant flies.

\section{Discussion}

We previously showed that AMN expression is required in the $\mathrm{MB}$ for Drosophila memory. Here, we establish that AMN expression in the $\mathrm{MB}$ is necessary for the synergistic activation of PKA observed on co-stimulation by dopamine and acetylcholine in the $\alpha$ lobe, a process that is thought to mimic the coincidence detection event underlying memory formation. Furthermore, our data demonstrate a functional interaction between AMN and Nep1, suggesting that Nep1 targets AMN degradation, thereby terminating AMN signaling.

Six different aversive memory phases that are spatially segregated have been described in Drosophila (Bouzaiane et al., 2015). Their formation relies on distinct neuronal circuits, as well as distinct molecular and cellular mechanisms (Comas et al., 2004; Blum et al., 2009; Pagani et al., 2009; Aso et al., 2012; Bouzaiane et al., 2015; Murakami et al., 2017). rut mutants are impaired in specific memory phases (Tully and Quinn, 1985; Han et al., 1992; Blum et al., 2009; Scheunemann et al., 2013), including short-term memory (STM), encoded in $\gamma \mathrm{KC}$, and MTM encoded in $\alpha / \beta \mathrm{KC}$ (Scheunemann et al., 2013; Bouzaiane et al., 2015). It was previously shown that Rut expression restricted to $\gamma \mathrm{KC}$ is sufficient to restore STM, but not MTM, in rut mutant flies (Akalal et al., 2006; Blum et al., 2009). It is thus likely that 
A 1-cycle (2 h) Females

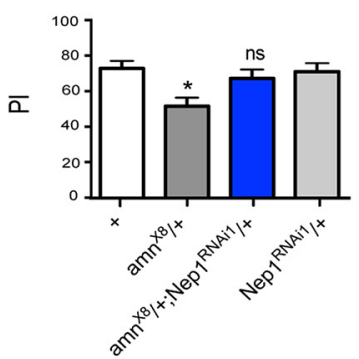

C 1-cycle (2 h) Females non-induced
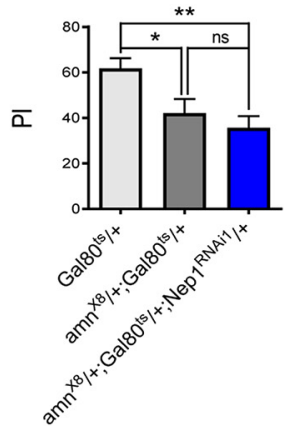

D Dopamine $10 \mu \mathrm{M}$ + Acetylcholine $10 \mathrm{mM}$

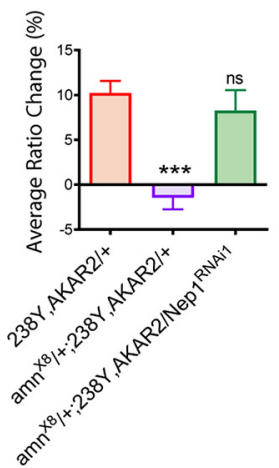

B

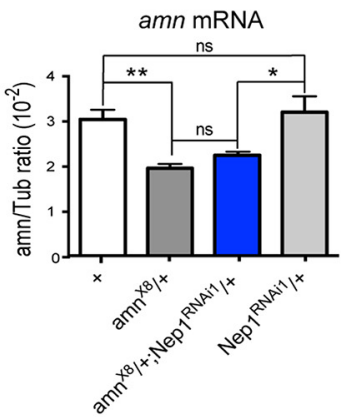

$\bar{\Sigma}$

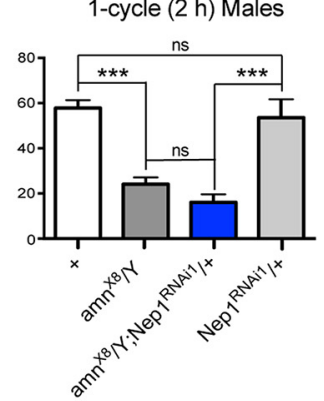

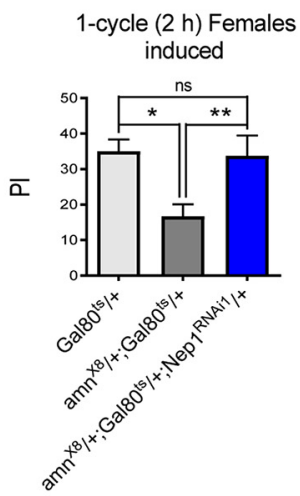
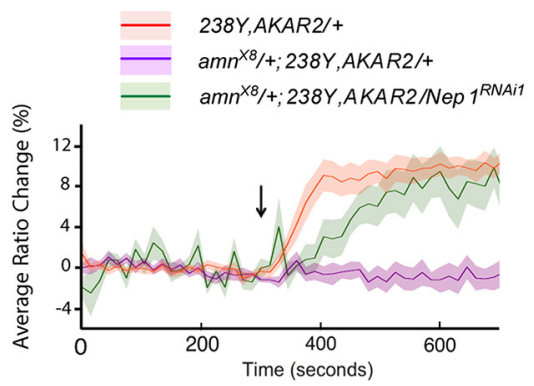

distinct Rut-mediated coincidence detection events occur in parallel in $\gamma$ and $\alpha / \beta \mathrm{KC}$, resulting in STM and MTM formation, respectively. Interestingly, mutants expressing a reduced amn level display normal STM (Turrel et al., 2018). Thus, AMN is most likely not required for the coincidence detection process that leads to STM, a process that remains to be identified. Using in vivo imaging, we previously showed that coapplication of dopamine and acetylcholine induces a strong synergistic PKA response, which is Rut dependent and occurs specifically in $\mathrm{MB}$ vertical lobes (Gervasi et al., 2010). Here, we show that this coincident PKA activation in the $\alpha$ lobe is abolished in amn mutants, while neither calcium signaling nor cAMP signaling following dopaminergic stimulation alone are altered. We propose that PKA activation mimics the coincidence detection event that occurs in $\alpha / \beta$ KC during MTM formation, and that AMN intervenes in this process by enabling a sustained Rut-mediated PKA activation in the $\mathrm{MB} \alpha$ lobe.

AMN might thus act at a step that ranges from the initial coincidence detection event that provokes Rut activation, to the final level of PKA activation. This is consistent with previous reports that $\mathrm{AMN}$ and $\mathrm{DC} 0$, the fly PKA catalytic subunit (Skoulakis et al., 1993), act in a common pathway, and that AMN function is upstream of DC0 function (Yamazaki et al., 2007). If AMN plays a role posterior to the coincidence detection event, it could be involved in an increase in cAMP concentration through the inhibition of phosphodiesterases that degrade cAMP. Indeed, dopamine receptors positively coupled to adenylate cyclases are equally distributed in all $\mathrm{MB}$ lobes as are DC0 and Rut (Han et al., 1992; Kim et al., 2003), whereas 100 $\mu \mathrm{M}$ dopamine only induces a PKA response in the $\alpha$ lobe. This spatial control is achieved by the cAMP-specific phosphodiesterase Dunce (Dnc; Byers et al., 1981; Davis and Kiger, 1981; Qiu et al., 1991) which preferentially degrades cAMP in the $\beta$ and $\gamma$ lobes, thus restricting high dopamineinduced PKA activation to the $\alpha$ lobe (Gervasi et al., 2010). AMN could thus be involved in the specific inhibition of Dnc in the $\alpha$ lobe.

One attractive alternative hypothesis is that AMN action could take place at the level of Rut activation itself. Indeed, the fact that one of the AMN peptides is 
A

$$
\begin{aligned}
& \text { 1-cycle }(2 \mathrm{~h}) \\
& \text { induced }
\end{aligned}
$$
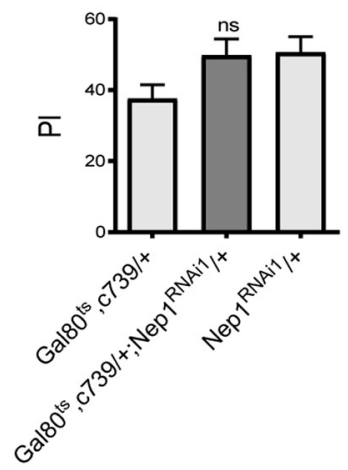

C

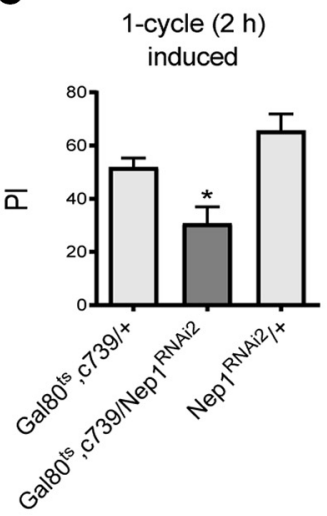

1-cycle (2 h) induced
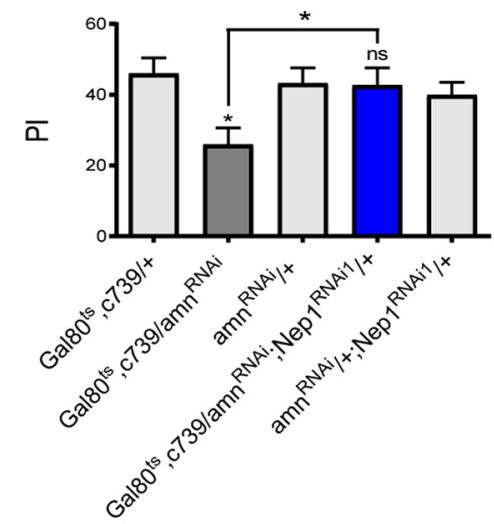

1-cycle $(2 \mathrm{~h})$

induced

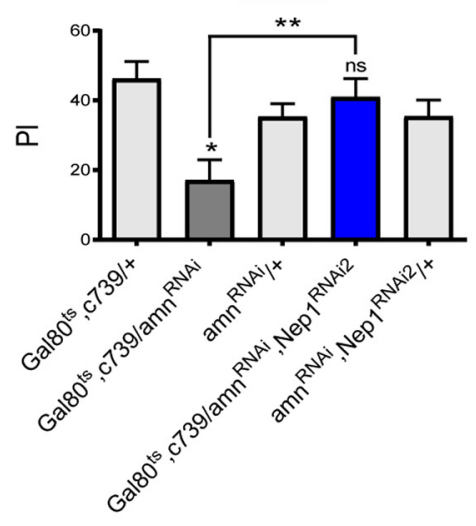

B



D

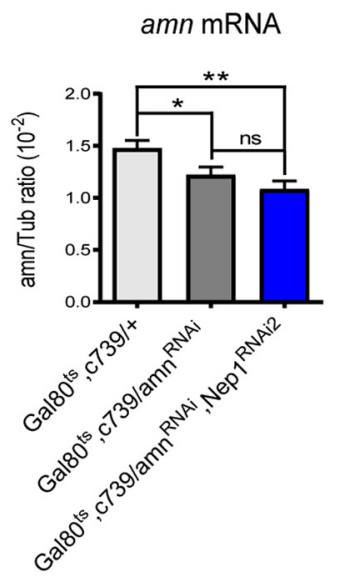

E

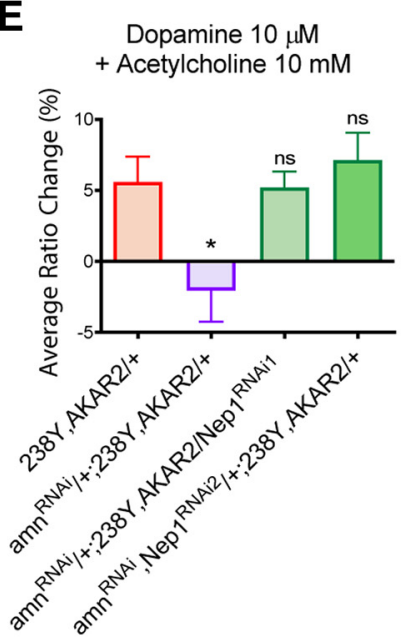

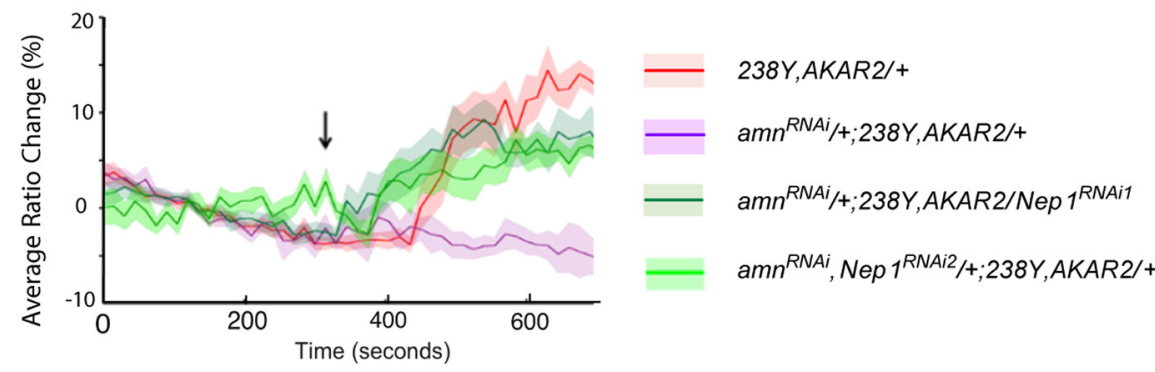

Figure 4. Nep1 knock-down in the adult MB of amn mutant flies restores wild-type MTM and PKA activation. A-D, Acute inhibition of Nep1 expression in the $\alpha / \beta$ KC of adult amn knocked down flies restores normal MTM. Flies were incubated for $3 \mathrm{~d}$ at $30^{\circ} \mathrm{C}$ to induce Nep1 and amn RNAi expression in the $\alpha / \beta \mathrm{KC}$ under the control of the c739 Gal4 driver. $A$, left panel,

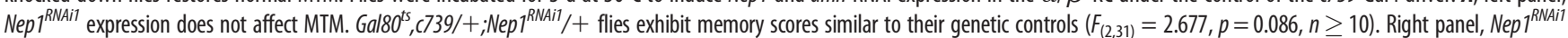



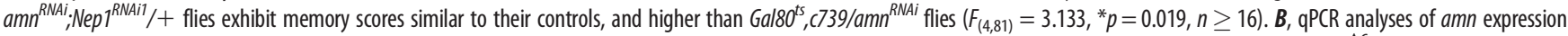
levels. Total RNA extracted from female heads was reverse-transcribed and further quantified by qPCR. Expression relative to the reference is expressed as a ratio $\left(2^{-\triangle C \text {, }}\right.$, where $C p$ is the cross-

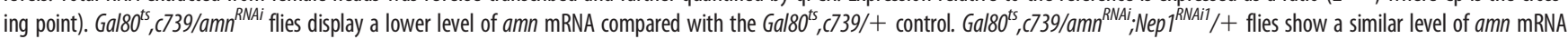
compared with Gal80 $0^{t 5}, 739 / a m n^{R N A i}$ flies $\left(F_{(2,27)}=4.214,{ }^{*} p=0.027, n \geq 8\right)$. Each bar corresponds to $8-10$ measurements from four to five independent experiments. $C$, left panel, Nep $7^{\text {RAAiz }}$ expression leads to an MTM deficit. Gal $80^{t 5}, 739 /$ Nep $^{\text {RNAi2 }}$ flies exhibit lower memory scores than their genetic controls $\left(F_{(2,32)}=9.83,{ }^{* * *} p=0.0005, n \geq 10\right)$. Right panel, Nep $7^{\text {RNAi2 }}$ acute

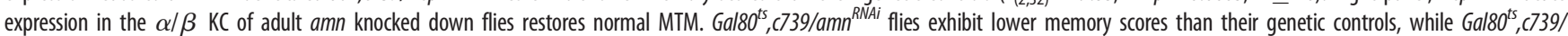

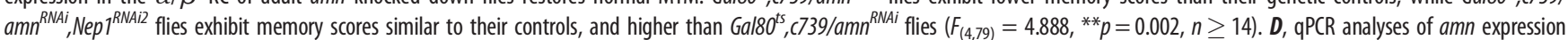
levels. Total RNA extracted from female heads was reverse-transcribed and further quantified by qPCR. Expression relative to the reference is expressed as a ratio $\left(2^{-\triangle C P}\right.$, where $C p$ is the 


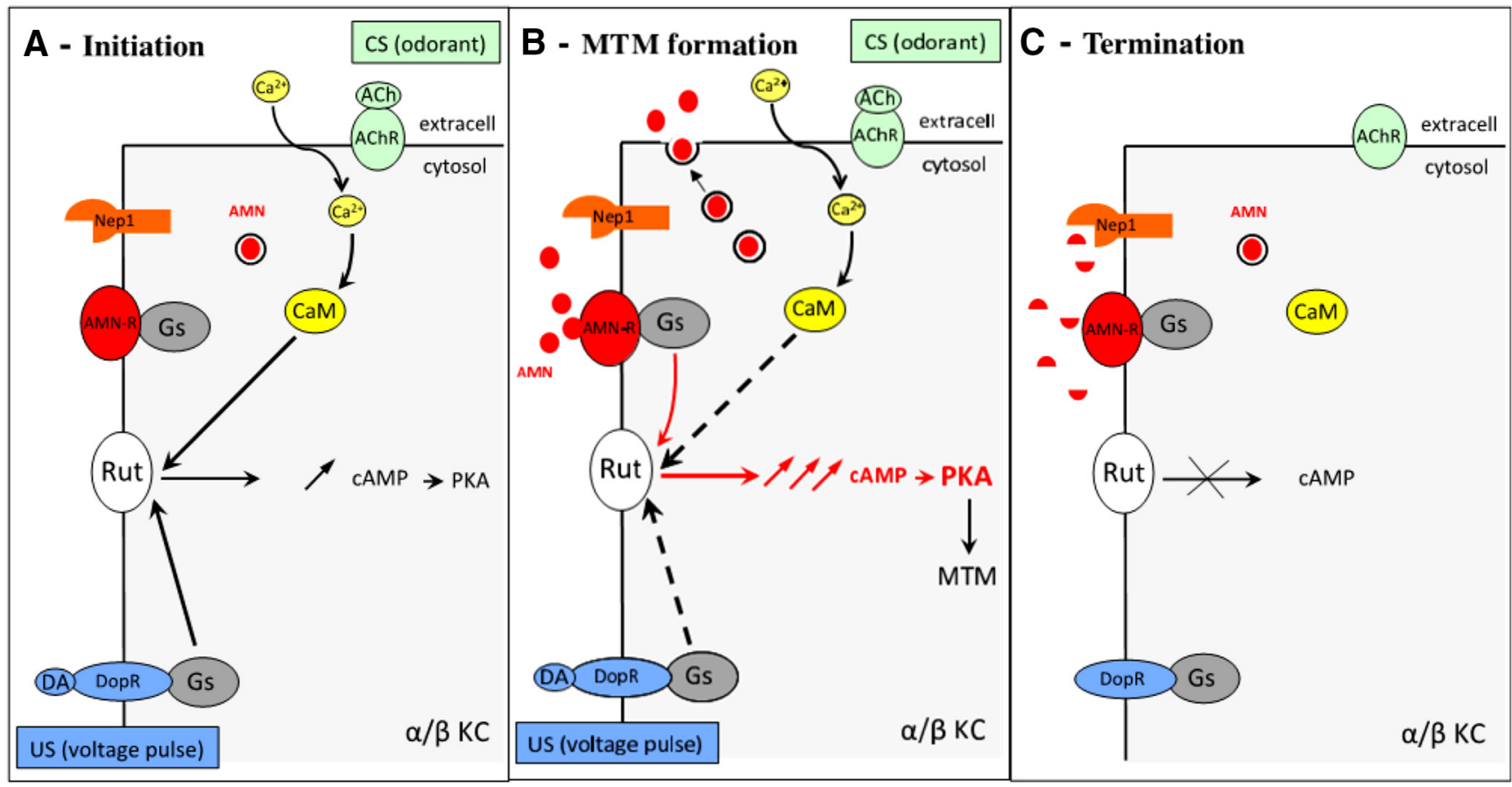

Figure 5. A model for the role of AMN and Nep1 in MTM formation. $\boldsymbol{A}$, Voltage pulse associated to odorant delivery generates coincidence detection. Initial Rut activation takes place. $\boldsymbol{B}$, Following the first CS/US association, initial PKA activation leads to AMN secretion that will further activate Rut. MTM is progressively building up. C, AMN signaling is terminated by Nep1.

homologous to PACAP suggests that AMN might play a role in activating the adenylate cyclase Rut through G-protein-coupled receptors. This hypothesis fits with sequence prediction (Feany and Quinn, 1995; Hashimoto et al., 2002), and is supported by studies showing that AMN is functionally related to human PACAP. It was initially reported that Rut is activated by the application of human PACAP-38 (Zhong, 1995, 1996), and later shown that bath application of PACAP-38 rescues L-type current deficiency in $a m n^{X 8}$ larval muscle fibers (Bhattacharya et al., 2004). Such rescue is abolished by application of an antagonist to Type-I PACAP-receptor as well as by application of an inhibitor of AC (Bhattacharya et al., 2004).

Although STM and MTM both rely on the cAMP/PKA pathway, not only these processes occur in separate $\mathrm{KC}$, but while STM is instantaneously acquired, MTM is acquired in a dynamic fashion following a two-step mechanism (Scheunemann et al., 2013). We propose that AMN function is specifically required in the incremental build-up of MTM by boosting Rut activation following the initial event of coincidence detection, namely the first $\mathrm{CS} / \mathrm{US}$ association of the training protocol. In this model, this first association results in an initial moderate level of Rut activation, followed by a moderate level of PKA activation (Fig. 5A).

$\leftarrow$

crossing point). Gal $80^{\text {ts }}, \mathrm{C} 739 / a m n^{\text {RNAi }}$ flies display a lower level of amn mRNA than the

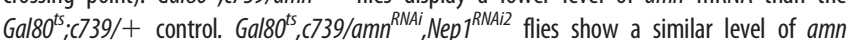
mRNA compared with Gal80, ${ }^{\text {ts }}, 739 / a m n^{R N A i}$ flies $\left(F_{(2,37)}=6.64,{ }^{* *} p=0.004, n \geq 12\right)$. Each bar corresponds to $12-14$ measurements from six to seven independent experiments. $\boldsymbol{E}$, Nep1 inhibition in flies expressing $a m n^{R N A i}$ in the MB restores normal PKA activation. The PKA AKAR2 FRET probe was expressed in the MB with the $238 Y$ driver. Left panel, Mean FRET ratio changes in the vertical lobe. Upon co-stimulation with dopamine and acetylcholine, $a m n^{R N A i}$ expression in the MB prevents PKA activation. Flies expressing $a m n^{R N A i}$ together with either Nep $7^{\text {RAii }}$ or Nep $7^{\text {RNAi2 }}$ show PKA activation similar to control flies $\left(F_{(3,32)}=\right.$ $5.165,{ }^{* *} p=0.006, n \geq 7$ ). Right panel, Grouped time course of FRET ratios. Graphs were produced using the same data as for the bar graph. The arrow indicates the time of neurotransmitter application. ns, not significant.
This moderate level of PKA activation does not mediate MTM formation and is below detection threshold. We hypothesize that this initial increase in PKA activity, directly or indirectly, triggers the second step of the process, namely AMN secretion, and thus generate an activation loop whereby AMN activates Rut, hence creating a much higher level of Rut activation and subsequent high levels of PKA activation that is observable with the AKAR2 probe (Fig. 5B). MTM formation would rely on an AMN-dependent PKA-activation loop terminated on AMN degradation by Nep1 (Fig. 5C).

One previous study has indicated that human PACAP is a substrate for hNEP (Gourlet et al., 1997), and our present work in Drosophila describes a functional interaction between AMN and Nep1. Importantly, whereas Nep1 knock-down rescues the amn mutant memory phenotype in a genetic context where the AMN level is reduced to $\sim 50 \%$ versus wild-type flies (heterozygous for the amn null allele), it fails to do so in a genetic context where AMN is absent (i.e., in flies hemizygous for the amn null allele). Namely, the memory rescue observed on Nep1 inhibition is dependent on the presence of AMN, suggesting that this latter is targeted by Nep1. While a biochemical confirmation of this hypothesis would be welcome, it is technically difficult to achieve. Specifically, not only are AMN antibodies not available, but amn mRNA is expressed at very low levels (Feany and Quinn, 1995; Chintapalli et al., 2007; Affymetrix data available at http://flyatlas.org/atlas.cgi?name=FBgn0000076), indicating that AMN peptide may be very scarce.

The observation that the AMN peptide may be targeted by Nep1 is in agreement with a neuromodulatory function. Once released, a signaling molecule must be removed from its site of action to prevent continued stimulation, and to allow new signals to propagate. If neurotransmitter's action is terminated either by diffusion, re-uptake by the presynaptic neuron, or enzymatic degradation, signaling neuropeptides are specifically removed by degradation. The intensity and duration of neuropeptide- 
mediated signals are thus controlled via the cleavage of these neuropeptides by peptidases like neprilysins. Despite a few exceptions (Bland et al., 2007; Meyer et al., 2009), neprilysins occur as integral membrane endopeptidases whose catalytic site faces the extracellular compartment (Nalivaeva and Turner, 2013). We hypothesize that on conditioning, $A M N$ is secreted by the $\mathrm{KC}$ to participate in Rut activation via G-protein-coupled receptors, and is ultimately removed from the extracellular compartment by Nep1 anchored at the KC membrane. Importantly, AMN expression in the MB restores normal PKA dynamics in amn null mutant flies, suggesting that the AMN peptide secreted by the $\mathrm{MB}$ on conditioning should act in an autocrine-like way to sustain Rut activity in the $\alpha / \beta$ neurons. Interestingly, the effects of neuropeptide transmitters are very diverse and often long-lived (Nässel, 2009), which fits well with the specific involvement of AMN peptide in non-immediate memory phases via sustained PKA activation.

Up to date, fly neprilysins have been involved in several behaviors: in the control of circadian rhythms, via hydrolysis of the pigment dispersing factor neurotransmitter (Isaac et al., 2007), and in the control of food intake via cleavage of insulin-like regulatory peptides (Hallier et al., 2016). In the latter study, it was shown that both Neprilysin 4 knock-down and overexpression in the larval CNS cause reduced food intake (Hallier et al., 2016). In a similar way, we show here that both Nep1 knock-down and overexpression in $\alpha / \beta$ KC impairs MTM, consistent with the need for a proper control of AMN levels. We suggest that Nep1 overexpression results in amn loss of function, whereas Nep1 knock-down causes the prolongation of AMN action, thus generating a prolonged activation of the cAMP/PKA pathway, a process deleterious for memory. This is in agreement with a previous study demonstrating that overexpressing DC0 in the MB impairs MTM (Yamazaki et al., 2007).

In conclusion, we report here an acute role for AMN in memory formation via the PKA pathway in the $\alpha / \beta$ MB neurons, a function modulated by Nep1. Our results thus support a role for $\mathrm{AMN}$ as an activating adenylate cyclase peptide, much like the role of PACAP, bringing clarity to the role PACAP may play in memory consolidation in mammals.

\section{References}

Akalal DB, Wilson CF, Zong L, Tanaka NK, Ito K, Davis RL (2006) Roles for Drosophila mushroom body neurons in olfactory learning and memory. Learn Mem 13:659-668.

Aldrich BT, Kasuya J, Faron M, Ishimoto H, Kitamoto T (2010) The amnesiac gene is involved in the regulation of thermal nociception in Drosophila melanogaster. J Neurogenet 24:33-41.

Arimura A (1998) Perspectives on pituitary adenylate cyclase activating polypeptide (PACAP) in the neuroendocrine, endocrine, and nervous systems. Jpn J Physiol 48:301-331.

Aso Y, Grübel K, Busch S, Friedrich AB, Siwanowicz I, Tanimoto H (2009) The mushroom body of adult Drosophila characterized by GAL4 drivers. J Neurogenet 23:156-172.

Aso Y, Herb A, Ogueta M, Siwanowicz I, Templier T, Friedrich AB, Ito K, Scholz H, Tanimoto H (2012) Three dopamine pathways induce aversive odor memories with different stability. PLoS Genet 8:e1002768.

Bhattacharya A, Lakhman SS, Singh S (2004) Modulation of L-type calcium channels in Drosophila via a pituitary adenylyl cyclase-activating polypeptide (PACAP)-mediated pathway. J Biol Chem 279:37291-37297.

Bland ND, Thomas JE, Audsley N, Shirras AD, Turner AJ, Isaac ER (2007) Expression of NEP2, a soluble neprilysin-like endopeptidase, during embryogenesis in Drosophila melanogaster. Peptides 28:127-135.

Bland ND, Pinney JW, Thomas JE, Turner AJ, Isaac ER (2008) Bioinformatic analysis of the neprilysin (M13) family of peptidases reveals complex evolutionary and functional relationships. BMC Evol Biol 8:16.
Blum AL, Li W, Cressy M, Dubnau J (2009) Short- and long-term memory in Drosophila require cAMP signaling in distinct neuron types. Curr Biol 19:1341-1350.

Bouzaiane E, Trannoy S, Scheunemann L, Plaçais P-Y, Preat T (2015) Two independent mushroom body output circuits retrieve the six discrete components of Drosophila aversive memory. Cell Rep 11:1280-1292.

Brand AH, Perrimon N (1993) Targeted gene expression as a means of altering cell fates and generating dominant phenotypes. Development 118:401-415.

Byers D, Davis RL, Kiger JA (1981) Defect in cyclic AMP phosphodiesterase due to the dunce mutation of learning in Drosophila melanogaster. Nature 289:79-81.

Chintapalli VR, Wang J, Dow JA (2007) Using FlyAtlas to identify better Drosophila melanogaster models of human disease. Nat Genet 39:715720.

Comas D, Petit F, Preat T (2004) Drosophila long-term memory formation involves regulation of cathepsin activity. Nature 430:460-463.

Crittenden JR, Skoulakis EM, Han KA, Kalderon D, Davis RL (1998) Tripartite mushroom body architecture revealed by antigenic markers. Learn Mem Cold Spring Harb 5:38-51.

Davis RL, Kiger JA Jr (1981) Dunce mutants of Drosophila melanogaster: mutants defective in the cyclic AMP phosphodiesterase enzyme system. J Cell Biol 90:101-107.

de Belle J, Heisenberg M (1994) Associative odor learning in Drosophila abolished by chemical ablation of mushroom bodies. Science 263:692-695.

Feany MB, Quinn WG (1995) A neuropeptide gene defined by the Drosophila memory mutant amnesiac. Science 268:869-873.

Fiala A, Spall T (2003) In vivo calcium imaging of brain activity in Drosophila by transgenic cameleon expression. Sci STKE 2003:PL6.

Gervasi N, Tchénio P, Preat T (2010) PKA dynamics in a Drosophila learning center: coincidence detection by Rutabaga adenylyl cyclase and spatial regulation by dunce phosphodiesterase. Neuron 65:516-529.

Gourlet P, Vandermeers A, Robberecht P, Deschodt-lanckman M (1997) Vasoactive intestinal peptide (VIP) and pituitary adenylate cyclase-activating peptide (PACAP-27, but not PACAP-38) degradation by the neutral endopeptidase EC 3.4.24.11. Biochem Pharmacol 54:509-515.

Hallier B, Schiemann R, Cordes E, Vitos-Faleato J, Walter S, Heinisch JJ, Malmendal A, Paululat A, Meyer H (2016) Drosophila neprilysins control insulin signaling and food intake via cleavage of regulatory peptides. Elife 5:e19430.

Han PL, Levin LR, Reed RR, Davis RL (1992) Preferential expression of the Drosophila Rutabaga gene in mushroom bodies, neural centers for learning in insects. Neuron 9:619-627.

Hashimoto H, Shintani N, Baba A (2002) Higher brain functions of PACAP and a homologous Drosophila memory gene amnesiac: insights from knockouts and mutants. Biochem Biophys Res Commun 297:427-432.

Isaac RE, Johnson EC, Audsley N, Shirras AD (2007) Metabolic inactivation of the circadian transmitter, pigment dispersing factor (PDF), by neprilysin-like peptidases in Drosophila. J Exp Biol 210:4465-4470.

Keene AC, Stratmann M, Keller A, Perrat PN, Vosshall LB, Waddell S (2004) Diverse odor-conditioned memories require uniquely timed dorsal paired medial neuron output. Neuron 44:521-533.

Kim YC, Lee HG, Seong CS, Han KA (2003) Expression of a D1 dopamine receptor dDA1/DmDOP1 in the central nervous system of Drosophila melanogaster. Gene Expr Patterns 3:237-245.

Levin LR, Han P-L, Hwang PM, Feinstein PG, Davis RL, Reed RR (1992) The Drosophila learning and memory gene Rutabaga encodes a $\mathrm{Ca} 2+$ calmodulin-responsive adenylyl cyclase. Cell 68:479-489.

Matsuyama S, Matsumoto A, Hashimoto T, Shintani N, Baba A (2003) Impaired long-term potentiation in vivo in the dentate gyrus of pituitary adenylate cyclase-activating polypeptide (PACAP) or PACAP type 1 receptor-mutant mice. Neuroreport 14:2095-2098.

McGuire SE, Le PT, Osborn AJ, Matsumoto K, Davis RL (2003) Spatiotemporal rescue of memory dysfunction in Drosophila. Science 302:1765-1768.

Meyer H, Panz M, Zmojdzian M, Jagla K, Paululat A (2009) Neprilysin 4, a novel endopeptidase from Drosophila melanogaster, displays distinct substrate specificities and exceptional solubility states. J Exp Biol 212:36733683.

Meyer H, Panz M, Albrecht S, Drechsler M, Wang S, Hüsken M, Lehmacher C, Paululat A (2011) Drosophila metalloproteases in development and 
differentiation: the role of ADAM proteins and their relatives. Eur J Cell Biol 90:770-778

Miyata A, Arimura A, Dahl RR, Minamino N, Uehara A, Jiang L, Culler MD, Coy DH (1989) Isolation of a novel 38 residue-hypothalamic polypeptide which stimulates adenylate cyclase in pituitary cells. Biochem Biophys Res Commun 164:567-574.

Mons N, Guillou J-L, Jaffard R (1999) The role of Ca2+/calmodulin-stimulable adenylyl cyclases as molecular coincidence detectors in memory formation. Cell Mol Life Sci 55:525-533.

Moore MS, DeZazzo J, Luk AY, Tully T, Singh CM, Heberlein U (1998) Ethanol intoxication in Drosophila: genetic and pharmacological evidence for regulation by the cAMP signaling pathway. Cell 93:997-1007.

Murakami S, Minami-Ohtsubo M, Nakato R, Shirahige K, Tabata T (2017) Two components of aversive memory in Drosophila, anesthesia-sensitive and anesthesia-resistant memory, require distinct domains within the Rgk1 small GTPase. J Neurosci 37:5496-5510.

Nalivaeva NN, Turner AJ (2013) Handbook of proteolytic enzymes, Ed 3, pp 612-619. San Diego: Academic Press.

Nässel DR (2009) Neuropeptide signaling near and far: how localized and timed is the action of neuropeptides in brain circuits? Invert Neurosci 9:57-75.

Pagani MR, Oishi K, Gelb BD, Zhong Y (2009) The phosphatase SHP2 regulates the spacing effect for long-term memory induction. Cell 139:186198.

Pascual A, Préat T (2001) Localization of long-term memory within the Drosophila mushroom body. Science 294:1115-1117.

Qiu Y, Chen C-N, Malone T, Richter L, Beckendorf SK, Davis RL (1991) Characterization of the memory gene dunce of Drosophila melanogaster. J Mol Biol 222:553-565.

Quinn WG, Sziber PP, Booker R (1979) The Drosophila memory mutant amnesiac. Nature 277:212-214.

Rubin GM, Hong L, Brokstein P, Evans-Holm M, Frise E, Stapleton M, Harvey DA (2000) A Drosophila complementary DNA resource. Science 287:2222-2224.

Russo AF (2017) Overview of neuropeptides: awakening the senses? Headache 57:37-46.

Sacchetti B, Lorenzini CA, Baldi E, Bucherelli C, Roberto M, Tassoni G, Brunelli M (2001) Pituitary adenylate cyclase-activating polypeptide hormone (PACAP) at very low dosages improves memory in the rat. Neurobiol Learn Mem 76:1-6.

Scheunemann L, Skroblin P, Hundsrucker C, Klussmann E, Efetova M, Schwärzel M (2013) AKAPS act in a two-step mechanism of memory acquisition. J Neurosci 33:17422-17428.

Schmidt SD, Myskiw JC, Furini CR, Schmidt BE, Cavalcante LE, Izquierdo I (2015) PACAP modulates the consolidation and extinction of the contextual fear conditioning through NMDA receptors. Neurobiol Learn Mem 118:120-124.

Shih MF, Davis FP, Henry GL, Dubnau J (2019) Nuclear transcriptomes of the seven neuronal cell types that constitute the Drosophila mushroom bodies. G3 (Bethesda) 9:81-94.
Sitnik JL, Francis C, Hens K, Huybrechts R, Wolfner MF, Callaerts P (2014) Neprilysins: an evolutionarily conserved family of metalloproteases that play important roles in reproduction in Drosophila. Genetics 196:781797.

Skoulakis EM, Kalderon D, Davis RL (1993) Preferential expression in mushroom bodies of the catalytic subunit of protein kinase A and its role in learning and memory. Neuron 11:197-208.

Tian L, Hires SA, Mao T, Huber D, Chiappe ME, Chalasani SH, Petreanu L, Akerboom J, McKinney SA, Schreiter ER, Bargmann CI, Jayaraman V, Svoboda K, Looger LL (2009) Imaging neural activity in worms, flies and mice with improved GCaMP calcium indicators. Nat Methods 6:875881.

Tomchik SM, Davis RL (2009) Dynamics of learning-related cAMP signaling and stimulus integration in the Drosophila olfactory pathway. Neuron 64:510-521.

Tully T, Quinn WG (1985) Classical conditioning and retention in normal and mutant Drosophila melanogaster. J Comp Physiol A Neuroethol Sens Neural Behav Physiol 157:263-277.

Turner AJ, Isaac RE, Coates D (2001) The neprilysin (NEP) family of zinc metalloendopeptidases: genomics and function. Bioessays 23:261-269.

Turrel O, Lampin-Saint-Amaux A, Préat T, Goguel V (2016) Drosophila neprilysins are involved in middle-term and long-term memory. J Neurosci 36:9535-9546.

Turrel O, Goguel V, Preat T (2017) Drosophila Neprilysin 1 rescues memory deficits caused by amyloid- $\beta$ peptide. J Neurosci 37:10334-10345.

Turrel O, Goguel V, Preat T (2018) Amnesiac is required in the adult mushroom body for memory formation. J Neurosci 38:0876-0818.

Vaudry D, Gonzalez BJ, Basille M, Yon L, Fournier A, Vaudry H (2000) Pituitary adenylate cyclase-activating polypeptide and its receptors: from structure to functions. Pharmacol Rev 52:269-324.

Waddell S, Armstrong JD, Kitamoto T, Kaiser K, Quinn WG (2000) The amnesiac gene product is expressed in two neurons in the Drosophila brain that are critical for memory. Cell 103:805-813.

Yamazaki D, Horiuchi J, Nakagami Y, Nagano S, Tamura T, Saitoe M (2007) The Drosophila DCO mutation suppresses age-related memory impairment without affecting lifespan. Nat Neurosci 10:478-484.

Zhang J, Ma Y, Taylor SS, Tsien RY (2001) Genetically encoded reporters of protein kinase A activity reveal impact of substrate tethering. Proc Natl Acad Sci USA 98:14997-15002.

Zhang J, Hupfeld CJ, Taylor SS, Olefsky JM, Tsien RY (2005) Insulin disrupts $\beta$-adrenergic signalling to protein kinase $\mathrm{A}$ in adipocytes. Nature 437:569-573.

Zhong Y (1995) Mediation of PACAP-like neuropeptide transmission by coactivation of RAS/Raf and cAMP signal transduction in Drosophila. Nature 375:588-592.

Zhong Y (1996) Genetic dissection of signal transduction mechanisms underlying PACAP-like neuropeptide transmission in Drosophila: synergy of cAMP and Ras/Raf pathways. Ann NY Acad Sci 805:67-79.

Zhong Y, Peña LA (1995) A novel synaptic transmission mediated by a PACAP-like neuropeptide in Drosophila. Neuron 14:527-536. 